\title{
The Experiences of Municipal Management on the Implementation of Performance Management Systems in Lepelle- Nkumpi Local Municipality, in Limpopo Province
}

\author{
Ms Kgomotlokoa Linda Thaba \\ University of Limpopo (Turfloop Campus, Mankweng), Private Bag X1106, Sovenga, 0727 \\ Kgomotlokoa.thaba@ul.ac.za \\ Dr. Maria Matshidiso Kanjere \\ University of Limpopo, Turfloop Graduate School of Leadership, P O Box 756, Fauna Park, 0787 \\ Maria.kanjere@ul.ac.za
}

\section{Doi:10.5901/mjss.2014.v5n27p1216}

\section{Abstract}

Performance Management Development System has been implemented at local municipalities to measure the performance of the workers and to indirectly combat poor service delivery protests. The program however brought its own inherent challenges. The question that remained was whether the system was effective in developing the workers or not. Thus, an empirical investigation was conducted in Lepelle- Nkumpi local municipality to explore the experiences of municipal management on the implementation of performance management system. The study also looked at the support systems that are in place for the implementation of the programme. Twenty six municipal managers participated in the study, thirteen females and thirteen males. The findings indicated that there is a need to improve on the implementation of Performance Management and Development Systems.

Keywords: Performance management system, development, appraisal, evaluation

\section{Introduction}

Service delivery protests in South African allude to a number of problems within the local government system. It was reported in the police database in 2004 and 2005 financial year that about 6000 service delivery protests took place in South Africa. Hence, it is imperative to reflect on the performance management systems that are in place as an attempt to find solutions to these problems. In 2001 the Department of Provincial and Local Government released the Performance Management Guide for municipalities. The argument which was presented was that work had to be measured so that corrections can be made where necessary and rewards be given. Thus, the Performance Management Development System (PMDS) was implemented.

Performance Management Development System is a system that includes various activities which ensure that goals are consistently met in an effective and efficient manner. It is a system that focuses on the performance of an organization, department, and employees and even on the processes build to give out a product or service. Swanepoel, Erasmas, Wyk, Schenk (2003: 382) argue that an effective performance management system should enable and empower line management to implement the strategy and objectives of the organisation successfully.

When the tool was first implemented, various results in various municipalities were recorded. However, the focus in this study is on Lepelle-Nkumpi municipality. As a point of departure relevant government literature, journal articles, books, websites and legislature were consulted to formulate conceptual framework and develop the elements of best practice.

\subsection{Development of Performance Management Systems in Limpopo Province}

In Limpopo Province, performance management system was developed in 2000 through Simeka Management Consulting. The company was assigned through the Integrated Provincial Support Programme to design and implement a Performance Management system for the whole province. The Simeka tested its product through piloting between February 2001 and February 2002, before it was implemented at a larger scale. 
A performance management system was deemed necessary in the Limpopo Province to address a wide range of challenges which include lack of service delivery and to addressing backlogs in largely rural and under-developed areas in the province and to implement the Provincial Growth and Development Strategy. The company through collaborative efforts developed a model that could be implemented in the province. The model which was adopted ensured that Performance Management System is practised in such a way that it is developmental and not punitive in nature. The model provided employees with career opportunities and allowed them to be creative and innovative in improving their performance.

\section{Conceptual Framework}

According to Amos, Ristow and Ristow (1999: 275), performance refers to employee's accomplishment of assigned tasks. In this study, performance refers to a detailed description and measurement of one's work output as described in the context of the organization's prescribed evaluation scorecard. It is a process of harnessing all available resources within an organization and ensuring that these perform to the maximum, in order to achieve the desired results. It is further indicated that Performance Management involves building processes, systems, culture and relationships that facilitate the achievement of organizational objectives. This implies the use of specific measurement tools. Thus, there is a difference between performance management and performance appraisal. "Performance management signifies an attempt to entrench performance appraisal as a legitimate and integral part of a manager's job of getting subordinates effectively achieve the results and goals expected of them" (Swanepoel et al., 2003: 375).

Deming (1987: 5) argues that performance appraisal as it is practised traditionally, hinders effective total quality management. Due to criticisms levelled against performance appraisal, its systems carry greatest risk of either falling, falling into disuse or degenerating towards a meaningless, paperwork exercise. Recent studies have shown that there is a shift of focus from performance appraisal to performance management. In performance management, the primary focus is on collection and utilization of the information for the purposes of measuring, evaluating and reporting on human resources' performance.

Muchinsky, Kriek and Schreuder (2005: 73) argue that performance management comprises the management of all performance related activities within the organisation, of which performance appraisal is only one of those activities. Spangenberg (1994: vii) describes performance management as a method used for conducting a performance reviews or appraisal and to change the culture of the organisation. Swanepoel et al., (2003:375) refer to performance management as an ongoing process that involves planning, managing, rewarding and development of performance. Appraisal is a component of performance management development system. It is an important factor in the success of the staff and organization. Romney's (2005:20) appraisal systems help in keeping track of the employees' skills development so as to determine their training needs.

\subsection{Performance measurement}

Pitt (1999:46) argues that the assessment measurement model facilitates the integration of a range of quality initiatives and progress with continuous improvements. Various performance management tools can be used to provide feedback on critical information such as a realistic view of an employee's strengths and development.

Wiggins (2005:1) states that the purpose of performance measurement is to find out what each employee is able to do. In addition, Laughlin (2000: 30) emphasized the importance of feedback in performance assessment. Thus, the identification and selection of measures is influenced by the level of accuracy of measurement required and the nature of the organization and its specific requirements. Regular performance evaluation is necessary as it improves the performance feedback of the employees. It helps the employees identify areas in which further training is necessary and where counselling has to be given. Therefore, for municipalities to perform, employees have to perform.

Copping (2000: 20) identifies various aspects of managerial behaviour that are claimed essential for appraisal success; namely, a thorough knowledge of subordinate's work, a belief that the individual can develop and change, the gathering of evidence about the subordinate's behaviour and performance, and making the time to conduct appropriate and meaningful appraisals and achieve appropriate development results. Monica (1999:43) identifies five main criteria by which to judge the usefulness of a performance assessment tool. The criteria include the extent to which the performance assessment tool allows human resource systems to be integrated with business strategy.

Performance assessment tool should also measure behavioural change and improvement. Wing (2000: 62) argues that to remove uncertainty that makes performance appraisal uncomfortable, clarification in several areas is necessary. Firstly, the employee objectives should not exceed five and should be measurable; and that they should not be too easy 
or too difficult. Secondly, the support needed to achieve these objectives should be clearly identified and appraisers be reminded that they should understand the employees' personal work goal and development needs.

Thirdly, the appraisal should define both the minimum satisfactory performance level and the reward that can be expected from exceeding it. Lastly, it was pointed out that regular feedback between appraisals is needed to adjust the construct if necessary. Grote (1998: 52) recommends three steps in performance measurement; namely, to ask employees to set some goals for the year; to ask employees to write at least a partial self- appraisal and to hold on a core vision you would like employees to remember. It should also be noted that a good performance appraisal system has to be relevance, sensitivity and accepted by all the employees.

Muchinsky, Kriek and Schreuder (1998: 169) outline some of the functions of performance appraisal tool stating that it enhances the quality of organisational decisions ranging from determining pay rises to promotions. If well implemented the performance management system enhances the quality of individual decisions which include career paths and development of future strengths. It provides employees with feedback on strengths and weaknesses and on how to improve their performance. The system helps the organizations to specify performance levels and training needs.

Spangenberg (1994:14) on the other hand identified four stages of performance management which are performance planning; review, and reward, which can be both informal and formal. Some performance management systems have graphic rating scales. Muchinsky et al., (1998: 177) identified some performance appraisal tools which included graphic rating scales. This is because assessing employees' job performance is an intricate process which is beset with a plethora of potential problems that have the capacity to muddle and defeat the very objectives that initiated it. They include organisational politics, gender and racial differences and goal pursued by different raters.

\section{Previous Research Conducted on Performance Measurement}

Amaratunga (2000:258) conducted a study on facilities management questions, to determine whether performance evaluation in fact does add value and enhance organizational performance. Performance appraisals which are often referred to as performance evaluation, merit rating, staff assessment, performance review or performance assessment are most often criticised and are said to carry the greatest risk of either failing, falling into disuse or degenerating towards a meaningless, paperwork exercise.

Moloney (2000:43) criticizes the current approach to developing competency frameworks in UK organizations, particularly the use of behavioural event interviews. He further argues that competencies should be tailored to the individual needs of an organization by paying attention to technical and conceptual doubts about the effectiveness of the approach. On interview and validation, he finds the approach potentially discriminatory. According to him, the cost of using consultants does not represent good value for money. Finally, he challenges the practice of relying on past behaviour, as this may not help organizational change.

Analoui (1999: 362) conducted a study in Ghana that involved senior managers working in organizations within the Ministry of Environment and Science. These were interviewed on the following aspects; perceptions of the qualities needed by an effective manager; the skills required; the criteria on which their effectiveness should be judged; motivators which promote effective management; the demands and constraints that prevent effective management; opportunities available for improving management effectiveness; the impact of the workplace environment; managerial effectiveness; and the influence of the dominant managerial philosophy within the organization. On the basis of the findings, it was possible to generate advice on organization-specific assessment tools for use in a public sector environment.

Deming (1987:55) identifies various problems with performance appraisal that show how enumerative management practices can be destructive. Firstly, it is assumed that a person being evaluated is responsible for results. Secondly, performance appraisal destroys teamwork, thirdly, performance appraisal fosters mediocrity and fourthly, it focuses on the short-term results and that it increases variability. It is said that it also destroys self-esteem, demotivates, builds fear and lowers productivity. McCall and De Vries (1994: 1), postulate three contextual factors that reduce the effectiveness of performance appraisal. These are the nature of the managerial work, organisational characteristics and environmental demands. Therefore, in line with the previous research that has been conducted on performance management systems, this study aim at probing the experiences of the management team in administering appraisals and managing performance.

\section{Empirical Study Conducted at Lepelle-Nkumpi Municipality}

Lepelle-Nkumpi Municipality is in Capricorn District which is one of the five districts of Limpopo Province and it is amongst the poorest local municipalities in the province. To this day quite a number of villages have limited access to electricity, 
sanitation and clean water. The municipality is predominantly rural with only one semi-urban area known as Lebowakgomo. Due to the high unemployment rate in the country and as well as in the province, most villages are poverty stricken. Thus, the main source of income is through social grants.

The sample size of 114 women in managerial positions was purposively selected from the group of 180 women managers' employed in strategic and operational managerial levels in the municipality. Permission to gain access to the research area was granted before interviews were conducted. Appointments were made with the participants so that their normal duties could not be interrupted. Interviews were conducted during lunch breaks.

The biographical information of the participants was captured, and thus the following table depicts the age distribution of the participants:

\subsection{Age distribution}

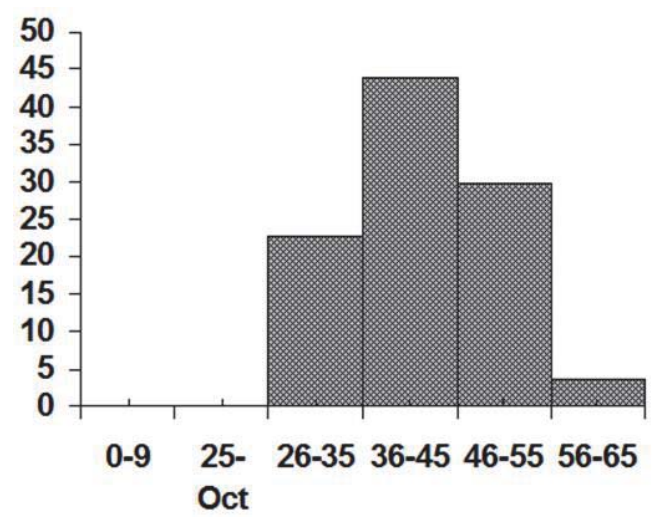

Figure 1: Age distribution

The table above shows that the age range of most women managers in the Lepelle Nkumpi Municipality is between 26 and 55 . This makes $96,5 \%$ of the sampled population. The middle-aged women managers form about $73,7 \%$ of the sampled population.

Participants were also asked to document their qualifications, experience prior to their appointments and any form of in-service training based on their performance. See the table below for presentation of facts.

\subsection{Educational qualifications}

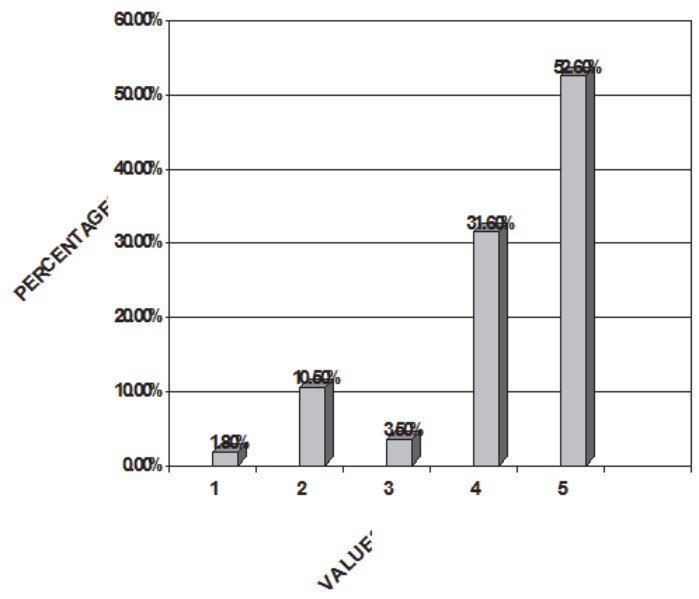

Figure 2: Educational qualifications

The values 1-5 in Figure 7 above represent Grade 10 and certificate course, Grade 12 only, Grade 12 and certificate course, Grade 12 and 3 year diploma/ degree and Grade 12 and postgraduate degree respectively. The histogram above depicts the educational qualification of the sampled population. Figure 8 indicates that more than $50 \%$ of the sample has 
Grade 12 and post graduate qualifications. Only 1.8\% of the sample has Grade 10 and the certificate course. The bar graph shows that $15,8 \%$ of the sample has qualifications below diploma or undergraduate degree. Most of women managers have Matriculation and diploma or higher qualifications.

\subsection{Prior managerial experience}

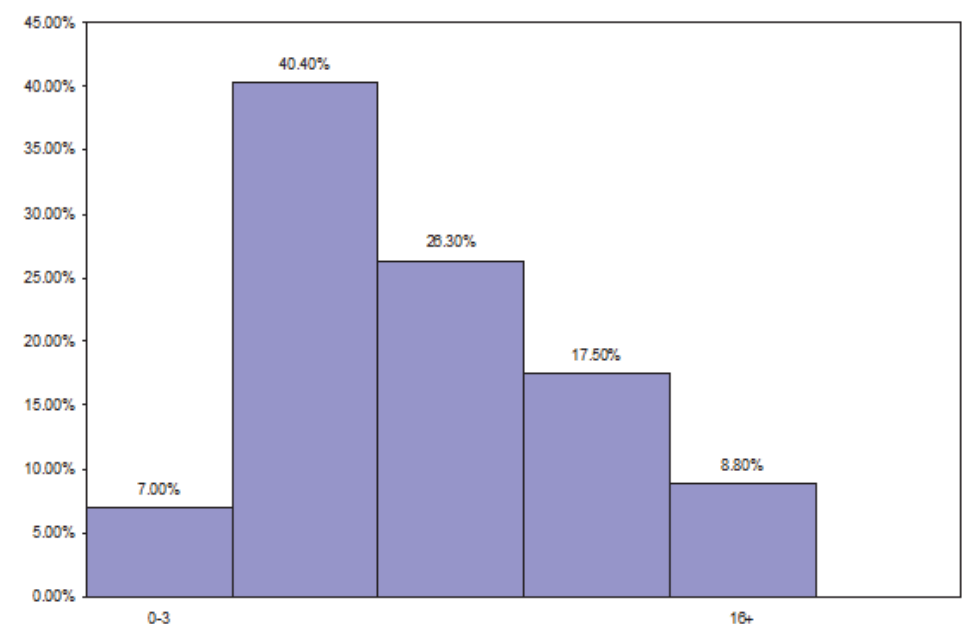

YEARS

Figure 3: Prior managerial experience

According to the histogram depicted on Figure 6 above, which represents a sampled population of women in managerial positions in the Lepelle- Nkumpi Municipality, only $7,1 \%$ of the sample represents women in managerial positions with managerial experience of 0-3 years before being appointed to the current post. At the range of $4-7$ years, $40,4 \%$ of the sampled population is found. The figure drops as the number of years increases. Thus, at the year range of 8-11years, 12-15 years and 16 years and above, the following were found, namely, 26,3\%, 17.5\% and $8.8 \%$, respectively. This indicates that the managerial experience of 4 years and more is required for most management positions that exist in the Lepelle- Nkumpi Municipality.

\subsection{In-service training}

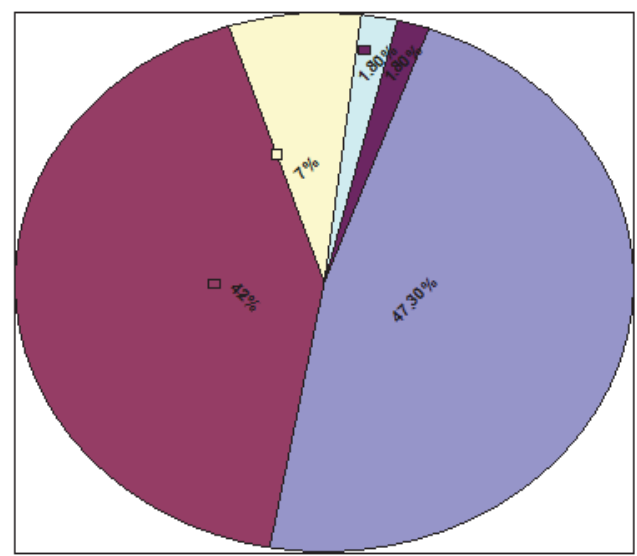

Figure 4: In-service training received

The figure given above indicates that the larger part of the pie, approximately half the pie, i.e., 170,28 degrees/ 47,3\%, have never received any in-service training since their appointment in their current managerial positions. While 151,56 degrees or $42,1 \%$ of the sample received only $1-3$ months in-service training. Those who received 6 months in-service 
training make only 25,2 degrees or 3,6\% of the sample. The deduction made from these data is that the Lepelle- Nkumpi Municipality provides very little in-service training.

\section{Results}

Most municipal management experienced challenges in relation to the implementation of Performance Management Development System. Managers were not well trained to conduct the appraisals. The on-job training for the advocacy and implementation of Performance Management Development System and its various performance instruments was very limited. The findings from the sampled data indicate that $87,8 \%$ of women managers received on-job-training schedules for 1 or 2 days only. If one has to check what a tool tries to achieve from the employees in various workplaces, the conclusion made is that the objectives the tool was meant to achieve were not met. Furthermore, it was noted that little support is given to women in management positions and individuals who are new in the organization.

\section{Conclusions}

The municipalities should put in place programs and systems to help with the implementation of performance management. This will enable the management to achieve their organizational goals. Support should also be given to the new employees through the induction programmes. Performance Management Systems as implemented to provide measuring standards in work place have to be reviewed.

Organizational performance is enhanced by individual performance. Individuals within municipalities will have to be empowered in such a way that they are able to execute their duties well. Management should also be adequately equipped to perform their duties.

\section{Recommendations}

The study generated the following recommendations which can also serve as guidelines for the implementation of future programmes:

(i) To provide in-service trainings to all employees at various ranks so as to enable them implement plans, policies and systems applicable to their work environment

(ii) To provide financial assistance to all the employees to further their studies at various higher education institutions

(iii) To give rewards to good performers so as to encourage high levels of performance and minimize ways of defrauding the system

(iv) To review the Performance Instruments yearly;

\section{References}

Amaratunga, D. 2000. Assessment of facilities Management performance. Property School of Construction and Property Management. 18 (4):258-266. (MCB University). http://www.mcbup.com/research_registers/jpif.asp

Amos, T. A., Ristow, P. \&Ristow, J.1999. Performance Assessment. Tokyo: Prentice Hall.

Analoui, F. 1999. Eight parameters of managerial effectiveness a study of senior managers in Ghana. Journal of Management Development (UK). Vol 18(4): 362- 379.

Copping, P. 2000. Appraisals: an approach for success. Training Journal (UK). Vol 1(1): 20- 22.

Grote, D. 1998. Painless performance focus on results, behaviours. HR Magazine Vol 43(1):52.

Laughlin, C. 2000. The trials, tribulations and traumas of feedback. Training Journal (UK). Vol 1(1): 30- 33.

Moloney, K. 2000. History repeating: competency frameworks). People Management. (UK). Vol 6(14): 43-45.

Monica, K.E. 1999. A product review: 360 Assessment. Training and Development (USA) Vol 53 (4): 43- 47.

Muchinsky, P.M. ; Kriek, H.J. \& Schreuder, D. 1998. Personnel Psychology. 2rd ed. Johannesburg: International Thompson publishing Pty Ltd.

Muchinsky, P.M., Kriek, H.J., \& Schreuder, D. 2005. Personnel Psychology 3 $3^{\text {rd }}$ ed. South Africa: Oxford University Press Southern Africa. Pitt, D.J. 1999. Improving performance through self-assessment. International Journal of Health Care Quality Assurance. Volume 12: 45- 54. Romney, P., Krom, K.,\& Hampton, M.M. 2002. Unpacking leadership. Centre for Gender in Organizations. Seminar series, 2001-2002. Spangenberg, H. 1994. Understanding and implementing performance management. South Africa: Juta Ltd.

Swanepoel, B., Erasmas, B., Van Wyk, M.,\& Schenk, H. 2003. South African Resource Management. Theory and Practice. 3rd Ed. South Africa : Juta.

Wing, K.T. 2000. Painless performance appraisal. Strategic Finance (USA). Vol 82(2): 62- 64. 